\title{
A Modified Anchor Taping Technique for Distal Onychocryptosis
}

\author{
Kathryn T. Shahwan, MD; Thomas Knackstedt, MD; David R. Carr, MD, MPH
}

Onychocryptosis most commonly affects the lateral nail folds and often can be treated with conservative measures, such as anchor taping. Distal onychocryptosis of the fingernail is less common and often is a delayed complication of nail surgery; treatment of this variant has not been as well described in the literature. We present a modified anchor taping method used to treat distal onychocryptosis of the fingernail.

\section{Practice Gap}

Onychocryptosis, colloquially known as an ingrown nail, most commonly affects the lateral folds of the toenails. It also can affect the fingernails and the distal aspect of the nail unit, though these presentations are not as well described in the literature. In onychocryptosis, the nail plate grows downward into the periungual skin, resulting in chronic pain and inflammation. Risk factors include overtrimming the nails with rounded edges, local trauma, nail surgery, wearing tight footwear, obesity, and onychomycosis. ${ }^{1}$

Although surgical intervention might be required for severe or refractory disease, conservative treatment options are first line and often curative. A variety of techniques have been designed to separate the ingrown portion of the nail plate from underlying skin, including placement of an intervening piece of dental floss, cotton, or plastic tubing. ${ }^{2}$

Anchor taping is another effective method of treating onychocryptosis; a strip of tape is used to gently pull and secure the affected nail fold away from the overlying nail plate. This technique has been well described for the treatment of onychocryptosis of the lateral toenail. ${ }^{3-5}$ In 2017, Arai and Haneke ${ }^{5}$ presented a modified technique for the treatment of distal disease.

We present a simplified method that was used successfully in a case of distal onychocryptosis of the thumbnail that occurred approximately 4 months after complete nail avulsion with a nail matrix biopsy (Figure 1).

\section{The Technique}

A strongly adhesive, soft cotton, elastic tape that is 1-inch wide, such as Elastikon Elastic Tape (Johnson \& Johnson),
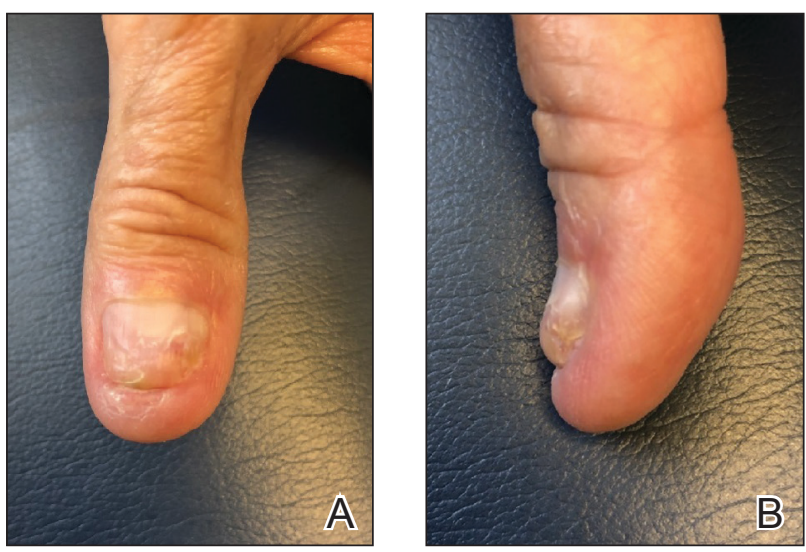

FIGURE 1. A and B, Distal onychocryptosis of the left first fingernail that occurred 4 months after complete nail avulsion and nail matrix biopsy.

Drs. Shahwan and Carr are from the Division of Dermatology, Department of Internal Medicine, The Ohio State University Wexner Medical Center, Columbus. Dr. Knackstedt is from the Department of Dermatology, MetroHealth Medical Center, Case Western Reserve University School of Medicine, Cleveland, Ohio.

The authors report no conflict of interest.

Correspondence: David R. Carr, MD, MPH, 540 Officenter PI, Ste 240, Gahanna, OH 43230 (david.carr@osumc.edu).

doi: 10.12788 /cutis.0330 

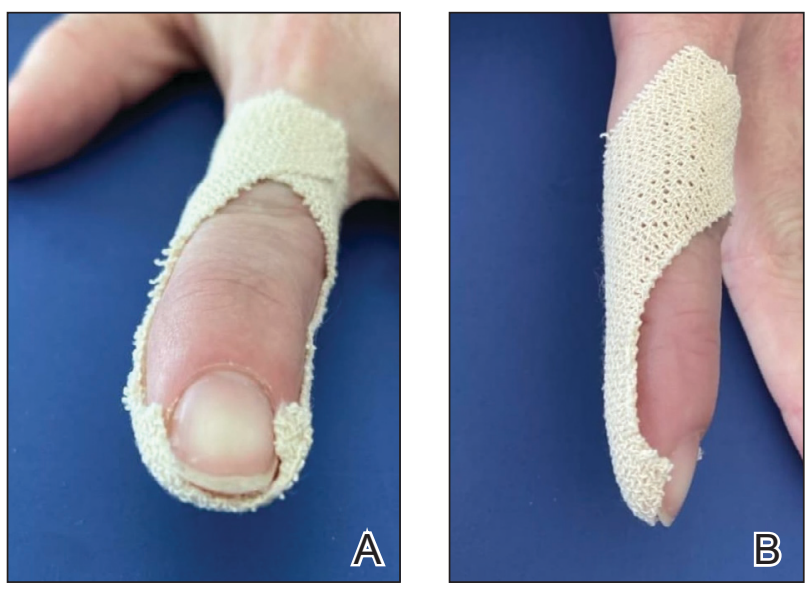

FIGURE 2. A and B, Modified anchor taping technique for distal onychocryptosis. Strongly adhesive, soft cotton, elastic tape that is 1 -inch wide is cut into 2 strips approximately 5 - $\mathrm{cm}$ long. The strips are applied in succession to the hyponychium, pulled in opposite oblique directions, and secured to opposing sides of the proximal digit.

is used to pull and secure the hyponychium away from the overlying nail plate. When this technique is used for lateral onychocryptosis, a single strip of tape is secured to the affected lateral nail fold, pulled obliquely and proximally, and secured to the base of the digit. ${ }^{3-5}$ In the Arai and Haneke ${ }^{5}$ method for the treatment of distal disease, a piece of tape is first placed at the distal nail fold, pulled proximally, and secured to the ventral aspect of the digit. Then, 1 or 2 additional strips of tape are applied to the lateral nail folds, pulled obliquely, and adhered to the base of the digit, as in the classic technique for lateral onychocryptosis. ${ }^{5}$

In our modification for the treatment of distal disease, only 2 strips of tape are required, each approximately 5 -cm long. The first strip of tape is applied to the hyponychium parallel to the long axis of the finger, pulled away from the distal edge of the nail plate, and secured obliquely and proximally to the base of the finger on one side. The second strip of tape is applied to the hyponychium in the same manner, directly overlying the first strip, but is then pulled obliquely in the opposite direction and secured to the other side of the proximal finger (Figure 2). The 2 strips of tape are applied directly overlying each other at the distal nail fold but with opposing tension vectors to optimize pull on the distal nail fold. This modification eliminates the need to apply an initial strip of tape along the long axis of the digit, as described by Arai and Haneke. ${ }^{5}$

The patient is instructed on this method in the office and will change the tape at home daily for 2 to 6 weeks, until the nail plate has grown out over the hyponychium (Figure 3). This technique also can be combined with
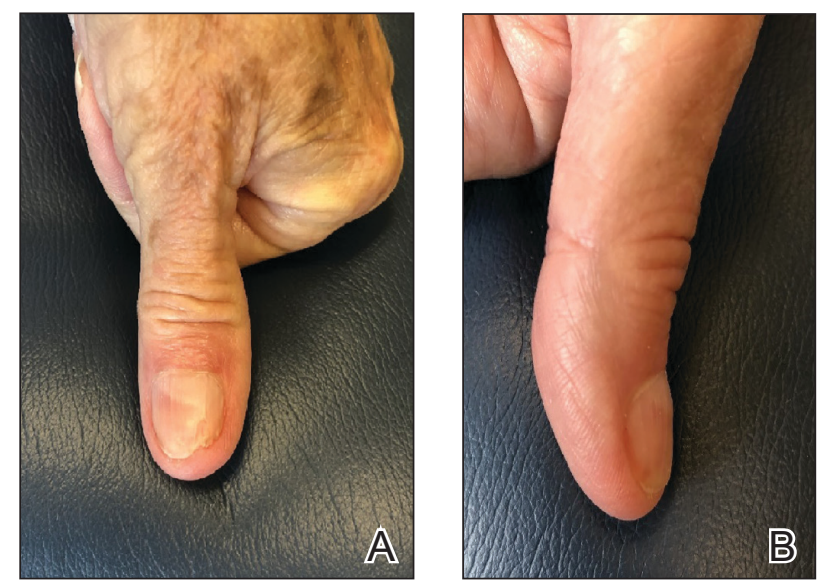

FIGURE 3. A and B, Notable improvement in distal onychocryptosis after only 2 weeks of using the modified anchor taping technique daily at home in combination with vinegar soaks.

other modalities, such as dilute vinegar soaks performed daily after changing the tape to ease inflammation and prevent infection. Because strongly adhesive tape is used, it also is recommended that the patient soak the tape before removing it to prevent damage to underlying skin.

\section{Practice Implications}

Anchor taping is a common and effective treatment of onychocryptosis. Most techniques described in the literature are for lateral toenail cases, which often are managed by podiatry. A modification for the treatment of distal onychocryptosis has been previously described. ${ }^{5}$ We describe a similar modification using 2 tape strips pulled in opposite directions, which successfully resolved a case of distal onychocryptosis of the fingernail that developed following a nail procedure.

Because nail dystrophy is a relatively common complication of nail surgery, dermatologic surgeons should be aware of this simple, cost-effective, and noninvasive technique for the treatment of distal onychocryptosis.

\section{REFERENCES}

1. Geizhals S, Lipner SR. Review of onychocryptosis: epidemiology, pathogenesis, risk factors, diagnosis and treatment. Dermatol Online J. 2019;25:13030/qt9985w2n0

2. Mayeaux EJ Jr, Carter C, Murphy TE. Ingrown toenail management. Am Fam Physician. 2019;100:158-164.

3. Tsunoda M, Tsunoda K. Patient-controlled taping for the treatment of ingrown toenails. Ann Fam Med. 2014;12:553-555. doi:10.1370/afm.1712

4. Watabe A, Yamasaki K, Hashimoto A, et al. Retrospective evaluation of conservative treatment for 140 ingrown toenails with a novel taping procedure. Acta Derm Venereol. 2015;95:822-825. doi:10.2340/00015555-2065

5. Arai H, Haneke E. Noninvasive treatment for ingrown nails: anchor taping, acrylic affixed gutter splint, sculptured nail, and others. In: Baran R, Hadj-Rabia S, Silverman R, eds. Pediatric Nail Disorders. CRC Press; 2017:252-274. 